\title{
A Chicken Model for DGCR6 as a Modifier Gene in the DiGeorge Critical Region
}

\author{
BEEREND P. HIERCK, DANIËL G.M. MOLIN, MARIT J. BOOT, ROBERT E. POELMANN, AND \\ ADRIANA C. GITTENBERGER-DE GROOT \\ Department of Anatomy and Embryology, Leiden University Medical Center, 2300 RC Leiden, The \\ Netherlands
}

\section{ABSTRACT}

\begin{abstract}
DGCR6 is the most centromeric gene in the human DiGeorge critical region and is the only gene in the region with a second functional copy on a repeat localized more distally on chromosome 22. We isolated the chicken ortholog of DGCR6 and showed an embryonic expression pattern that is initially broad but becomes gradually restricted to neural crest cell derivatives of the cardiovasculature. Retrovirus based gene transduction was used to deliver sense and antisense messages to premigrating neural crest cells in vivo. Embryos in which DGCR6 expression was attenuated revealed cardiovascular anomalies reminiscent of those found in DiGeorge syndrome. Moreover, the expression profiles of three other genes from the DiGeorge critical region, $T B X-1, U F D 1 L$, and HIRA, were shown to be altered in this model. $T B X-1$ and $U F D 1 L$ levels were increased, whereas HIRA was decreased in the hearts and pharyngeal arches of embryos treated with antisense or partial sense constructs, but not with sense constructs for DGCR6. The expression changes were transient and followed the normal DGCR6 expression profile. These data show that neural crest cells might have a role in the distribution of modulator signals to the heart and pharyngeal
\end{abstract}

arches. Moreover, it shows a repressor function for DGCR6 on the expression of $T B X-1$ and UFDIL. For the first time, DiGeorge syndrome is shown to be a contiguous gene syndrome in which not only several genes from the critical region, but also different cell types within the embryo, interact in the development of the phenotype. (Pediatr Res 56: 440-448, 2004)

$\quad$ Abbreviations
DGS, DiGeorge syndrome
DORV, double outlet right ventricle
EGFP, enhanced green fluorescent protein
IAA-B, interruption of the aortic arch-type B
IRES, internal ribosomal entry site
ISH, in situ hybridization
LTR, long terminal region
NCC, neural crest cells
PFA, paraformaldehyde
PTA, persistent truncus arteriosus
VSD, ventricular septal defect

Congenital anomalies can provide important clues for the impact of specific processes in embryonic development. With respect to the chromosome 22 deletion syndrome or DGS (OMIM 188400), a patient's phenotype is clearly related to disturbance of migration or differentiation of neural crest. This might also be evoked by an inadequate interaction with surrounding cells like the endo- and mesoderm in the pharyngeal arches. In DGS patients, cardiovascular anomalies often coincide with thymic, thyroid, and parathyroid defects (1). All these areas are populated by cephalic and cardiac NCC that delaminate from the dorsal neural tube during neurulation and enter the mesodermal compartment of the embryo (2-5). The chicken NCC ablation model (6) shows that these neural crest

Received May 30, 2003; accepted April 5, 2004.

Correspondence: Adriana C. Gittenberger-de Groot, Ph.D., M.D., Department of Anatomy and Embryology, Leiden University Medical Center, P.O. Box 9602, 2300 RC Leiden, The Netherlands; e-mail: A.C.Gittenberger-de_Groot@LUMC.nl

Supported by a grant from the Netherlands Heart Foundation (NHS 98.082).

DOI: 10.1203/01.PDR.0000136151.50127.1C areas are preferentially disturbed in DGS. In this respect, it is remarkable that, of the cardiovasculature in DGS patients, primarily the cardiac outflow tract and the fourth pharyngeal arch arteries are affected, although all arch arteries as well as outflow and inflow tracts of the heart are invaded by NCC (5, 7). The DGS phenotype in general presents with IAA-B, PTA, VSD, and tetralogy of Fallot $(8,9)$.

Although the affected chromosomal region has been known for over a decade, pinpointing the gene(s) involved in DGS is difficult. Genomic analysis of patients revealed a hemizygously typical deleted region of 1.5 - to $3.0-\mathrm{Mb}$ on chromosome 22 q1.1 carrying over 30 genes. This region appears highly unstable due to the presence of AT-rich sequences (10) and low copy repeats (11). To date, four genes within this region have been described as candidate genes: HIRA (12), UFD1L (13, 14), $C R K L$ (15), and $T B X-1$ (16-18). Of these genes, $T B X-1$ is the most promising, as hemizygously deleted mice show severe abnormalities in pharyngeal arch development (16). However, Tbx-1 is not expressed in NCC, and, despite large-scale genetic 
screenings (18), only one patient has been described with a $\sim 750$-kb deletion that encompasses the $3^{\prime}$ end of TBX-1 (19). Possible explanations for these discrepancies are i) the involvement of embryonic cell types other than NCC in the etiology of DGS, ii) the presence of cis-acting elements in the TBX-1 region regulating its expression "at distance" (20), or iii) modifier genes of the phenotype like Vegf (21) or Fgf-8 (22-24). In fact, identification of haplo-insufficiency of genes on chromosome 22q11 in "nondeleted" DGS patients turns out to be extremely complicated. Besides the case mentioned above, this has only been described for one patient that was deleted in UFD1L and CDC45L (13).

Animal models have been described with DGS-type congenital cardiovascular malformations, but none of the genes involved localize to human chromosome 22q1.1. These models include null mutants for endothelin-1 (25), endothelin receptor-A (26), endothelin converting enzyme-1 (27), transforming growth factor $\beta 2$ (28), mesenchyme forkhead genes $M f h-1 /$ Foxc2 (29) and Mf-1/Foxcl (30), Pax3 (31), Semaphorin-3C (32), vascular endothelial growth factor (VEGF165 (21)), and Fgf-8 (22-24). Most likely, they represent downstream genes involved in cardiovascular development that are controlled by elements on $22 \mathrm{q} 1.1$.

In this study, we describe the chicken ortholog of DGCR6. In humans, this gene is located at the most centromeric border of the DiGeorge critical region, and within a $75-\mathrm{kb}$ repeat located more distally (11). DGCR6, which shows sequence homology to the Drosophila gonadal protein GDL and to the laminin- $\gamma 1$ chain, has been shown to be deleted in DGS patients, and is highly expressed in heart and striated muscle (33). During murine embryogenesis, Dgcr6 shows a widespread distribution with highest expression in the pharyngeal arches and central and peripheral nervous system (34). We show in chicken embryos that DGCR6 is expressed in NCC and their derivatives, like vascular smooth muscle cells and cardiac ganglion cells. Using a retrovirus-based gene delivery system in vivo, DGCR6 expression was disturbed, specifically in premigrating chicken NCC, as has been recently described for UFDIL (14). The attenuation of DGCR6 resulted in cardiovascular anomalies reminiscent of those found in DGS. In addition, expression profiles of TBX-1, UFDIL, and HIRA were analyzed in the pharyngeal arches and in the hearts of treated embryos. DGCR6 appeared to modify the expression of all three DiGeorge candidate genes in a distinct but transient manner. We conclude that DGCR6 represses normal TBX-1 and UFDIL expression and stimulates HIRA, and may therefore be considered as modifier in the contiguous gene cascade that leads to DGS.

\section{METHODS}

Isolation of chicken DGCR6. To isolate chicken DGCR6, $10^{6}$ plaque-forming units (pfu) from a chicken heart cDNA library (Stratagene, Heidelberg, Germany) were screened with the human DGCR6 cDNA (kindly provided by S. Demczuk, Montreal). Four positive clones spanning the complete cDNA were subcloned using the lambda ZAP excision procedure, and were automatically sequenced on both strands. DGCR6 se- quence information is available in the GenBank database (accession number AF048985).

ISH and immunostaining. ${ }^{35} \mathrm{~S}$-based ISH on sections were performed as described previously $(35,36)$. DIG-based ISH on embryos in whole mount and on sections were essentially performed as described (37), with minor modifications. Briefly, prehybridization treatment included digestion with $10 \mu \mathrm{g} / \mathrm{mL}$ proteinase-K, re-fixation in $4 \% \mathrm{PFA} / 0.2 \%$ glutaraldehyde, and preincubation in $50 \%$ formamide solution containing $5 \times \mathrm{SSC}$, $1 \%$ SDS, $50 \mu \mathrm{g} / \mathrm{mL}$ tRNA, and $50 \mu \mathrm{g} / \mathrm{mL}$ heparin, at $55^{\circ} \mathrm{C}$. Overnight hybridization to DIG-labeled antisense cRNA probes (DIG RNA labeling kit, Roche Molecular Biochemicals, Mannheim, Germany) at $55^{\circ} \mathrm{C}$ was followed by posthybridization washes and detection with an alkaline phosphataseconjugated antiserum (1:500, Roche Molecular Biochemicals) and NBT/BCIP staining.

Embryos were fixed with 4\% PFA, embedded in paraffin, and sectioned for standard immunohistochemistry with the HNK-1 antibody (Developmental Studies Hybridoma Bank, Iowa City, IA, U.S.A.), tissue culture supernatant diluted 1:20 in PBS with $0.05 \%$ Tween-20 and $0.5 \%$ BSA. Visualization was performed by incubation with horseradish peroxidaseconjugated rabbit-anti-mouse antiserum (1:200, DAKO, Glostrup, Denmark), followed by staining with $0.04 \%$ diaminobenzidine tetrahydrochloride $/ 0.06 \% \mathrm{H}_{2} \mathrm{O}_{2}$ in $0.05 \mathrm{M}$ Trismaleic acid ( $\mathrm{pH}$ 7.6).

Retroviral constructs. The pro-retroviral pCXIZ (38) vector was kindly provided by Dr. T. Mikawa (New York, NY, U.S.A.), and was used as backbone for retroviral constructs. Full-length DGCR6 cDNA (nucl. 117-1247) was cloned in sense and antisense direction between the 5'-long terminal region (LTR) and the IRES (internal ribosomal entry site), which preceded the $L a c Z$ marker gene and the 3'-LTR of pCXIZ. The partial sense construct for DGCR6 (nucl. 3611248) gives rise to an N-terminal truncated product that lacks the putative transmembrane region, inasmuch as translation will start at nucleotide 603. CXL that contains LacZ under retroviral LTR control (39) was used as control virus.

All retroviral constructs were stably transfected to the D17.2G helper cell line. In vivo infection of premigrating NCC was performed at stage $\mathrm{HH} 9-11$, as has been described $(5,7)$. All animal studies have been approved by the Institutional Review Board. After reincubation embryos were fixed in 4\% PFA and stained for the $L a c Z$ gene product. In conjunction with recent reports (40-42), it appeared that LacZ expression from the IREScontaining retroviral constructs was sparse and tissue specific. To bypass this drawback, the presence of infectious retroviral particles was demonstrated using RT-PCR of in vitro incubated R2 rat fibroblasts with i) conditioned medium from nonproducing packaging cells (negative control); ii) conditioned medium from DGCR6-antisense retrovirus producing cells (containing LacZ); and iii) conditioned medium from CXL producing cells. In vivo transduction was demonstrated using cDNA from microdissected hearts (HH24 and HH31), pharyngeal arch mesenchyme ( $\mathrm{HH} 24)$, and from the proximal parts of the arch arteries (HH31) of infected and control embryos. Total RNA was isolated (RNAzol, Campro-Scientific, Veenendaal, The Netherlands), treated with DNAse-I, and $5 \mu \mathrm{g}$ was used for random hexamer-primed first- 
strand cDNA synthesis. Equal amounts of cDNA were PCR amplified with primers for LacZ (5'- gcgcagcetgaatggcgaatg-3'; 5'-gcaccacagatgaaacgccgag-3'), DGCR6 (5'-ctgctggagatccagcacc3'; 5'-catccatcattcgctgctcc-3'), IRES (5'-ccttattccaagcggettc-3'), and GAPDH (5'-gcacgccatcactatcttccag-3'; 5'-ccagacggcaggtcaggtcacc-3'). All samples were subjected to 35 rounds of PCR $\left(94^{\circ} \mathrm{C}\right.$ for $30 \mathrm{~s}, 60^{\circ} \mathrm{C}$ for $30 \mathrm{~s}, 72^{\circ} \mathrm{C}$ for $45 \mathrm{~s}$ ) with $10 \mathrm{pmol}$ of appropriate primers. To identify the distribution patterns of infected NCC, transduction was performed with a mixture of DGCR6-antisense virus and CXL, and with CXL alone, followed by X-gal staining (immersion in PBS containing $10 \mathrm{mM}$ potassium ferricyanide, 10 $\mathrm{mM}$ potassium ferrocyanide, $2 \mathrm{mM} \mathrm{MgCl}_{2}$, and $0.1 \%$ [wt/vol] $\mathrm{X}$-gal) of the embryos. Migration was distinct and matched the patterns as described for CXL alone.

In vitro demonstration of antisense effect. Constructs were prepared in which full-length $D G C R 6$ was cloned in sense and antisense orientation at the 3 ' end of EGFP in the pEGFP-N1 vector (CLONTECH, Palo Alto, CA, U.S.A.). These constructs were used to transfect the packaging cells that produce the sense DGCR6-IRES-LacZ carrying retrovirus (see above). Transfection was performed by electroporation of 25,000 cells with $10 \mu \mathrm{g}$ supercoiled plasmid DNA, by applying one 20-ms pulse of $200 \mathrm{~V}$ in a 4-mm cuvette (GenePulser Xcell, Bio-Rad, Hercules, CA, U.S.A.). EGFP expression was assessed after $48 \mathrm{~h}$ of culture with a fluorescence microscope (Leica Microsystems, Inc., Deerfield, IL, U.S.A.) and the area of expression was determined with Labworks software (UVP Labworks 4.0 (UVP Ltd., Cambridge, U.K.). The area ratios between EGFPDGCR6-antisense and -sense constructs in the packaging cell line were measures for the inhibiting effect of EGFP expression caused by the hybridization of sense and antisense DGCR6.

Real-time $\boldsymbol{R T}$-PCR. Embryos were grouped according to treatment, i.e. untreated, CXL, DGCR6-antisense, DGCR6-partial sense, DGCR6-sense (each group $n=5$ ), and total RNA was isolated from microdissected hearts and arches of stage $\mathrm{HH} 24$ and HH31 embryos (see above). Primer design and SYBR green PCR analysis were performed according to ABI protocols (Applied Biosystems, Foster City, CA, U.S.A.) and run on an ABI PRISM 7700 Sequence Detector (Applied Biosystems). The following primers, 10 pmol of each, were used: GAPDH (5'-ggggaaagtcatccctgag-3'; 5'-ggcaggtcaggtcaacaac-3'), TBX-1 (5'-gcactaccacccggactc-3'; 5'-cgttatcgtccagcaggtt-3'), UFD1L (5'-tcgcaaaggggtagtgtgt-3'; 5'-gaggcactgtcaccaggag-3'), and HIRA (5'-caggctgatgatcggagtt-3'; 5'-ccctccacactcgtcaaag-3'). Equal amounts of cDNA (see above) were amplified using 40 PCR cycles of $95^{\circ} \mathrm{C}$ for $15 \mathrm{~s}, 60^{\circ} \mathrm{C}$ for $30 \mathrm{~s}$, and $72^{\circ} \mathrm{C}$ for $30 \mathrm{~s}$, preceded by a hot start at $95^{\circ} \mathrm{C}$ for $10 \mathrm{~min}$. Four log dilutions of control cDNA (untreated HH24 embryo) were used to analyze the linearity of amplification $\left(R^{2}>0.95\right)$ for each set of primers and was included in every analysis as positive control. Melt-down analysis was included to test for aspecific PCR amplicons and was additionally checked by ethidium-bromide-stained agarose gel electrophoresis (no additional products were found; data not shown).

Embryos of the same age group were subjected to analysis of the DiGeorge candidate genes (TBX-1,UFD1L, and HIRA) and $G A P D H$ in one and the same real-time RT-PCR run. Crossing of threshold $(\mathrm{Ct})$ values obtained for the experimental genes were normalized against each own GAPDH value (43). $t$ Test $(p<0.05)$ analysis was applied to test for significance of gene-expression differences between DGCR6-retrovirus and CXL treated groups. Values of untreated and CXL-treated groups were not significantly different from each other $(p>$ 0.95 , not shown). Analyses were repeated three times and no significant interexperimental differences were obtained (not shown).

\section{RESULTS}

Structural analysis of DGCR6. We isolated the chicken variant of DGCR6 (Genbank AF048985; Fig. 1a) and show a high degree of conservation between human, mouse, and chicken sequences (Fig. 1b). Homology was restricted to residues 280-801 matching $83 \%$ with its human ( $80 \%$ on cDNA) and murine homologues $(79 \%$ on cDNA). Structurally, the predicted protein shows a single transmembrane domain (residues 50-69) predicted by the "DAS"-transmembrane prediction server (http://www.sbe.su.se/ miklos/DAS), a potential tyrosine kinase domain (residues 18-24), and several protein kinase-C phosphorylation sites (residues 76-78, 82-84, and 195-197), suggesting a receptor-like function. N-terminals of the arginine residue at position 18 in chicken, human, and mouse sequences are essentially nonhomologous. Moreover, in the chicken and mouse sequences, the stop loci are conserved, whereas the predicted human peptide is 22 residues longer. Further homology searches revealed minor identity to the Drosophila gonadal protein gene $g d l$.

Expression of DGCR6 during chicken embryogenesis. DGCR6 mRNA is expressed in a variety of cells during the initial stages of chicken development, revealing higher signal in the dorsal part of the neural tube and the mesoderm adjacent to the endoderm (Fig. 2a). At HH18, the embryos showed expression in NCC-populated areas, like the pharyngeal arches and the frontonasal mesenchyme (Fig. 2, $b$ and $c$ ). Moreover, the endothelium lining the arch arteries is positive for DGCR6 (Fig. 2d). At HH28, high amounts of DGCR6 message were found in ectoderm-derived tissues, like the ventral horn of the neural tube, and in neural crest derivatives, such as the spinal ganglia, and the smooth muscle cells of the pharyngeal arch arteries (Fig. 2, $e-h$ ). At stage HH44, vascular expression was diminished (not shown), and cardiac expression became restricted to the parasympathetic ganglia (Fig. 2, $i-k$ ), as confirmed by HNK-1 immunostaining (Fig. $2 l$ ).

Targeting NCC with retroviral DGCR6 constructs. Retroviral constructs carrying antisense and (partial) sense chicken DGCR6 were prepared and tested in vitro for infection properties. Rat fibroblasts were incubated with viral preparations and transduction was demonstrated with RT-PCR (Fig. 3a). Transduction in vivo was tested similarly by RT-PCR on embryonic tissues. $\mathrm{LacZ}$ was demonstrated in embryos of which NCC were infected with DGCR6-sense and -antisense virus, and with CXL control virus, but not in noninfected embryos (Fig. 3b). In vitro analysis of inhibition of expression by antisense DGCR6 showed a $41-53 \%$ reduction in EGFP expression upon transfection of cells producing the DGCR6sense retrovirus with the EGFP-DGCR6-antisense construct (not shown). Potential disturbance in migration patterning of 
A

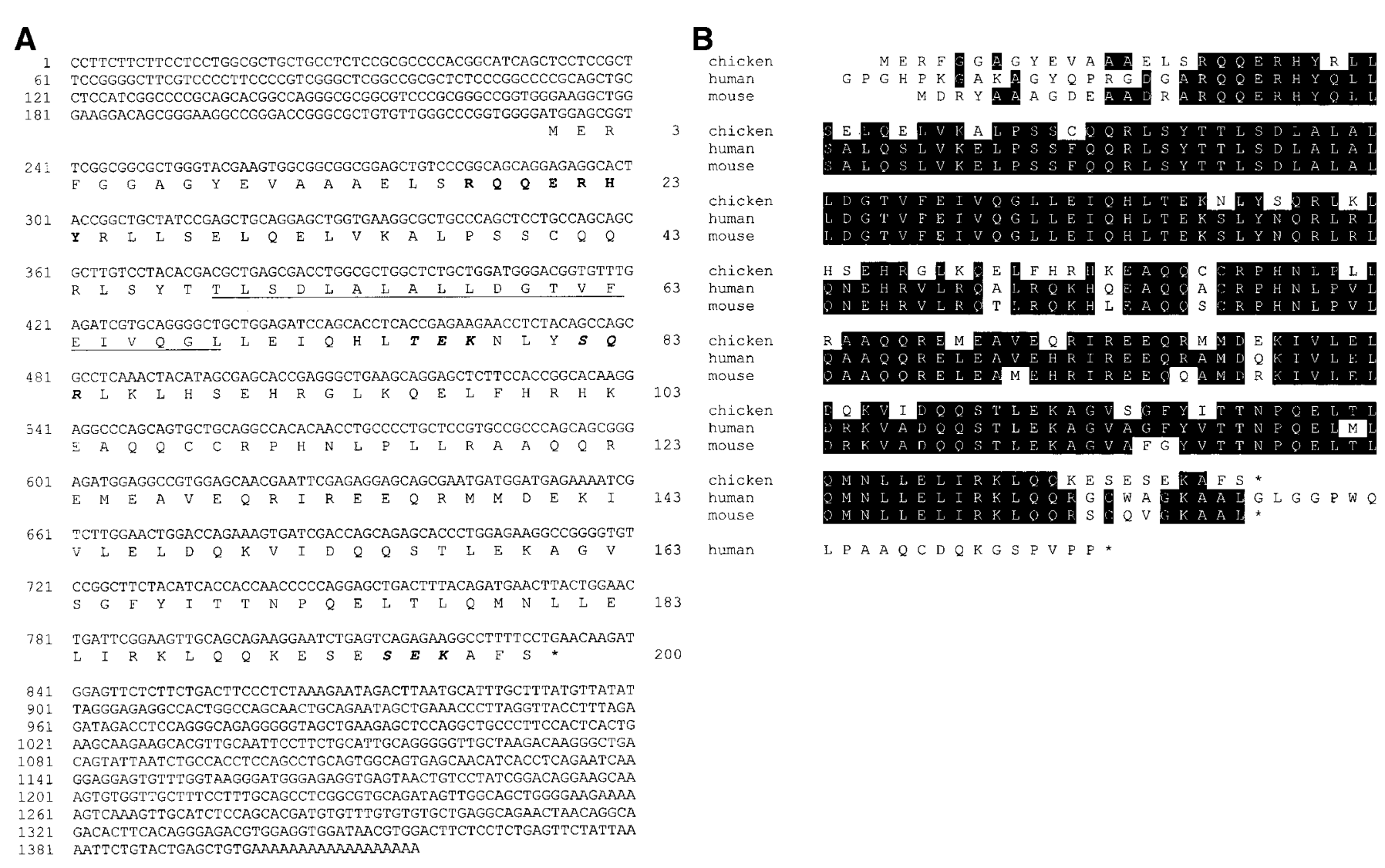

B

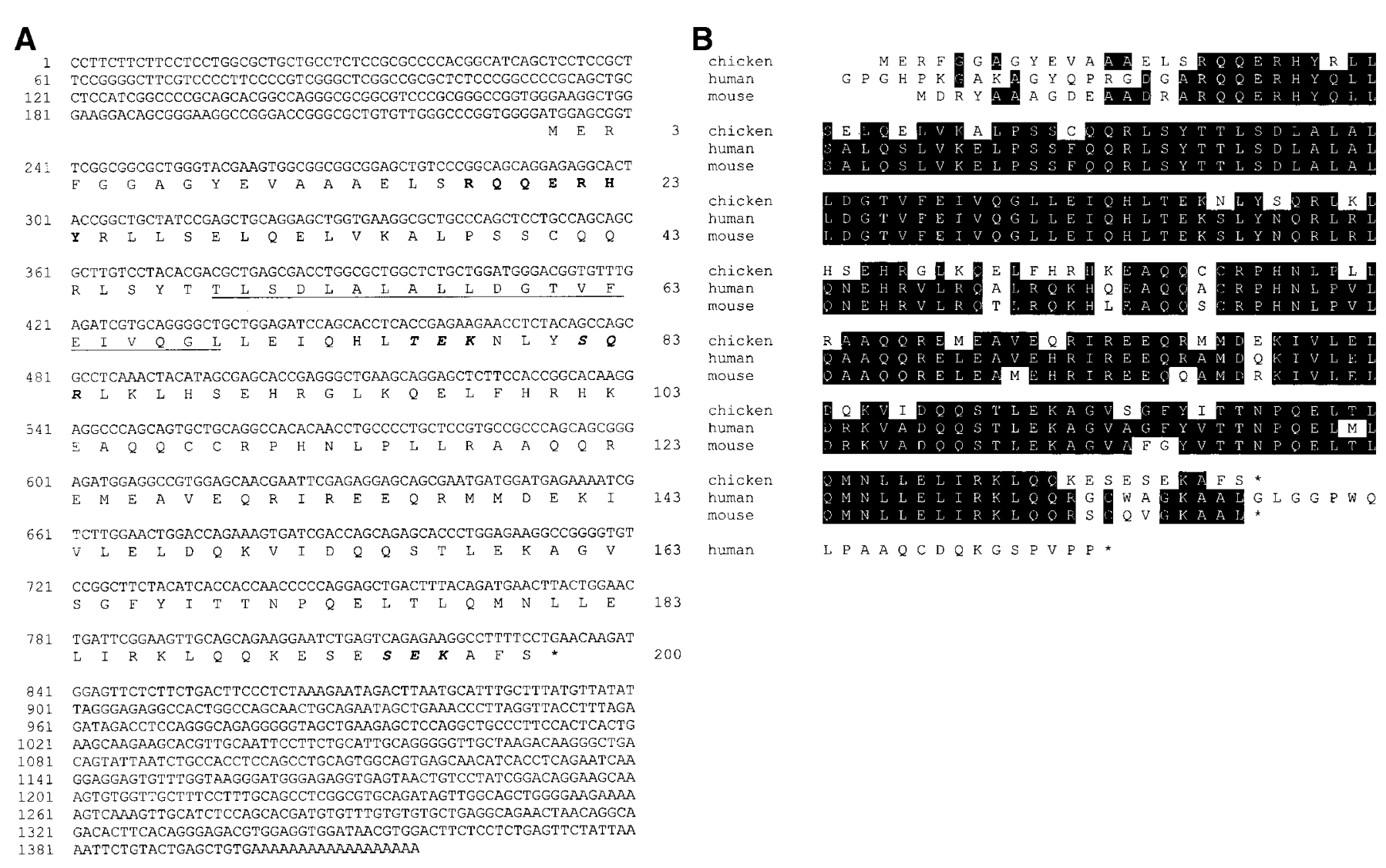

Figure 1. Chicken DGCR6. (a) cDNA sequence and deduced amino acid sequence of chicken DGCR6. A potential tyrosine kinase phosphorylation site is shown in boldface. The underscored sequence represents a putative transmembrane domain. Three potential protein kinase-C domains are italicized in boldface. Chicken DGCR6 cDNA sequence is available at Genbank (AF048985). (b) Alignment of chicken, human (×96484), and murine (AF021031) DGCR6 protein sequences. Homologous amino acids are boxed. The 5 ' phosphorylation site and the transmembrane region are conserved.

NCC infected with the DGCR6-antisense retrovirus was analyzed by double infection of premigrating NCC with the antisense and CXL viruses. Infected NCC were identified by $\mathrm{X}$-gal staining and staining patterns were compared with those of embryos that were treated with CXL alone (Fig. 3, $c$ and $d$ ). TUNEL analysis on sections of these embryos did not reveal changes in pattern or frequency of apoptosis within infected cell populations (not shown). This shows that the presence of sense or antisense mRNA for DGCR6 does not affect cell death and migration patterns of NCC.

Cardiovascular morphology upon retroviral infection. Transduction of premigrating NCC with antisense retroviral constructs for $D G C R 6$, and with a partial sense construct for $D G C R 6$, resulted in a high incidence of severe cardiovascular anomalies (Table 1). These anomalies became apparent during the remodeling stages of the vasculature, i.e. from stage $\mathrm{HH} 28$ onward, but were never identified earlier. The use of overexpression constructs, i.e. full-length sense constructs of which expression was driven by the retroviral promoter elements, as well as LacZ-containing control viruses, did not result in the anomalies induced by the attenuation of DGCR6. The phenotype designated subarterial ventricular septal defect in the setting of a double outlet of the right ventricle was present in $45 \%$ of the embryos treated with DGCR6-antisense and in $68 \%$ treated with the partial sense construct. It was characterized by an abnormal right-sided position of the aorta (in Fig. 4, com- pare $a$ and $c$ with $b$ and $d$ ) and a severely hypoplastic and ventrally displaced ventricular outflow tract septum. The latter resulted in an abnormal communication between left and right ventricles in the outflow segment of the heart up to the semilunar valve level (Fig. 4, $e-h$ ). No defects above this level, which would be typical for PTA, were found.

Vascular dysmorphic features were present within the group of embryos of which the NCC were transduced with the DGCR6-antisense and -partial sense viruses in 16\% and 23\% of the cases, respectively (Table 1). During normal development, the right ventricle in the avian embryo is bilaterally connected to the dorsal (descending) aorta through the left and right sixth pharyngeal arch arteries. Blood from the left ventricle runs through the right fourth arch artery (ascending aorta) and left and right third arch (brachiocephalic) arteries into the embryo (Fig. 5, $b, d$, and f). The left fourth arch artery normally regresses between HH26 and HH31. The most severe end of the spectrum of phenotypes induced by DGCR6-antisense or -partial sense transduction included regression of the right fourth arch artery (Fig. 5, $a, c$, and $e$ ) or anomalous persistence of the left fourth arch artery (not shown). Consistent with DGS and other animal models for this syndrome, especially the fourth, and not the third and sixth arch arteries appeared prone to abnormalities.

DiGeorge gene expression analysis. Real-time RT-PCR analysis was performed to determine gene expression profiles 


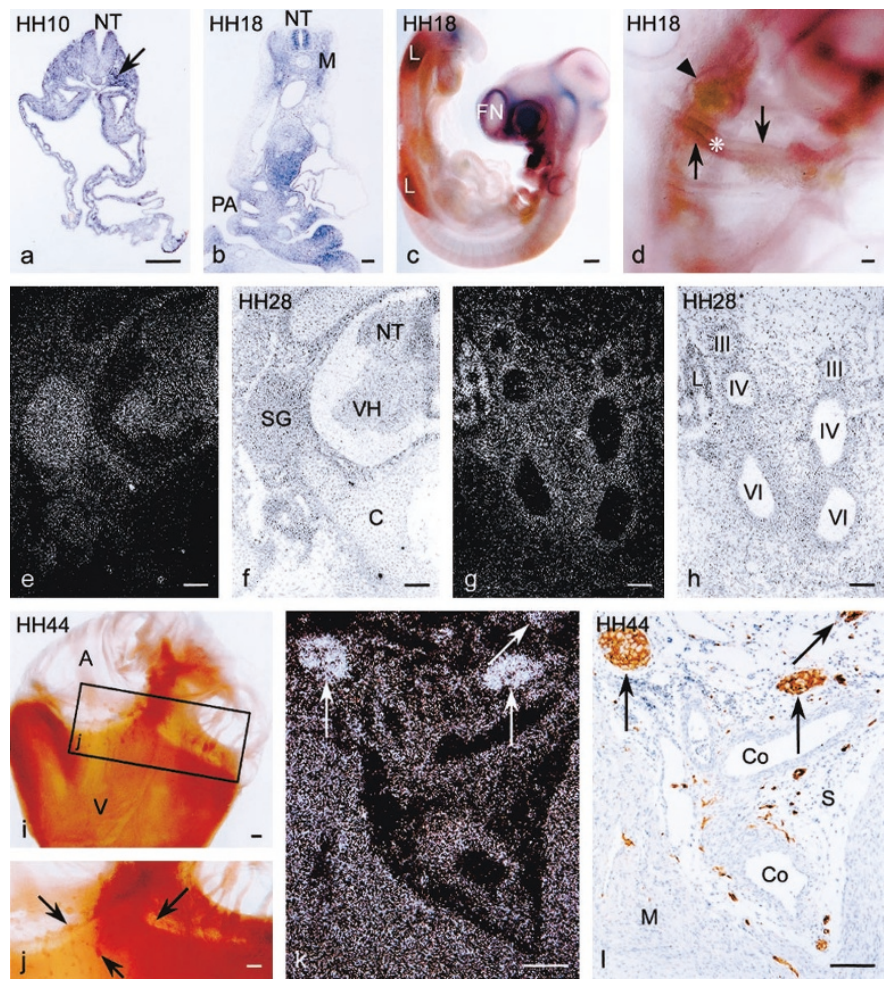

Figure 2. Expression patterns of DGCR6. (a) ISH for chicken DGCR6 at stage HH10. Note high expression in the dorsal part of the neural tube (NT), and in the lateral mesoderm facing the endoderm (arrow). Bar $=10 \mu \mathrm{m} .(b)$ ISH showing high levels of DGCR6 expression at HH18 in the NT, the myotome $(M)$, and in the neural crest derived mesenchyme of the pharyngeal arches $(P A)$. Bar $=10 \mu \mathrm{m}$. (c) At HH18, DGCR6 expression was found in the eye, the frontonasal mesenchyme $(F N)$, and in the limb buds $(L)$. Bar $=100$ $\mu \mathrm{m}$. (d) DGCR6 is not only expressed in the PA (asterisk), but also in the endothelial lining of the arch arteries (arrows), and of the dorsal aorta (arrowhead) at HH18. Bar $=10 \mu \mathrm{m} .(e, f)$ Darkfield $(e)$ and brightfield $(f)$ micrograph of the NT and adjacent tissues at stage HH28. DGCR6 expression is evident in the spinal ganglia $(S G)$, and in the ventral horn $(V H)$ of the neural tube ectoderm. $C$, cartilage. Bar $=10 \mu \mathrm{m} .(g, h)$ PA in dark $(g)$ and brightfield (h) show DGCR6 expression in the mesenchymal condensations surrounding the third (III), fourth $(I V)$, and sixth $(V I)$ arch arteries. Lung tissue $(L)$ is also positive. Bar $=10 \mu \mathrm{m} .(i, j)$ Whole-mount ISH of the HH44 heart, showing DGCR6 expression in the cardiac ganglia (arrows) that are localized in the sulcus mesenchyme between the atria $(A)$ and ventricles $(V)$. Bar $=100 \mu \mathrm{m}$. $(k, l)$ ISH for DGCR6 $(k)$ and immunostaining with the HNK-1 antibody that identifies neural crest cells and nervous tissue $(l)$ on consecutive sections show co-localization in the cardiac ganglia (arrows). $M$, myocardium; Co, coronary artery; $s$, sulcus mesenchyme. Bar $=10 \mu \mathrm{m}$.

of three other DiGeorge candidate genes, TBX-1, UFD1L, and HIRA in morphologically affected regions of the heart and arch arteries in DGCR6-retrovirus treated embryos. Relative mean expression ratios, i.e. expression values normalized to $G A P D H$, are outlined in Figure 6. Compared with CXL control virus treatment, transduction with $D G C R 6$-antisense and -partial sense constructs lead to an increase in $T B X-1$ and UFD1L in the heart and aortic arch mesenchyme at stage HH24 $(p<$ $0.05)$. In contrast, HIRA was down-regulated to $63-50 \%$ (heart) and $30-0.1 \%$ (arches) in these two groups of embryos. The use of DGCR6-sense constructs never resulted in significant changes in gene expression, except in the heart at HH24 for TBX-1 ( $p=0.04$, Fig. $6 a)$. However, biologic significance of this small increase, i.e. $15 \%$ compared with $81 \%$ and $93 \%$ in
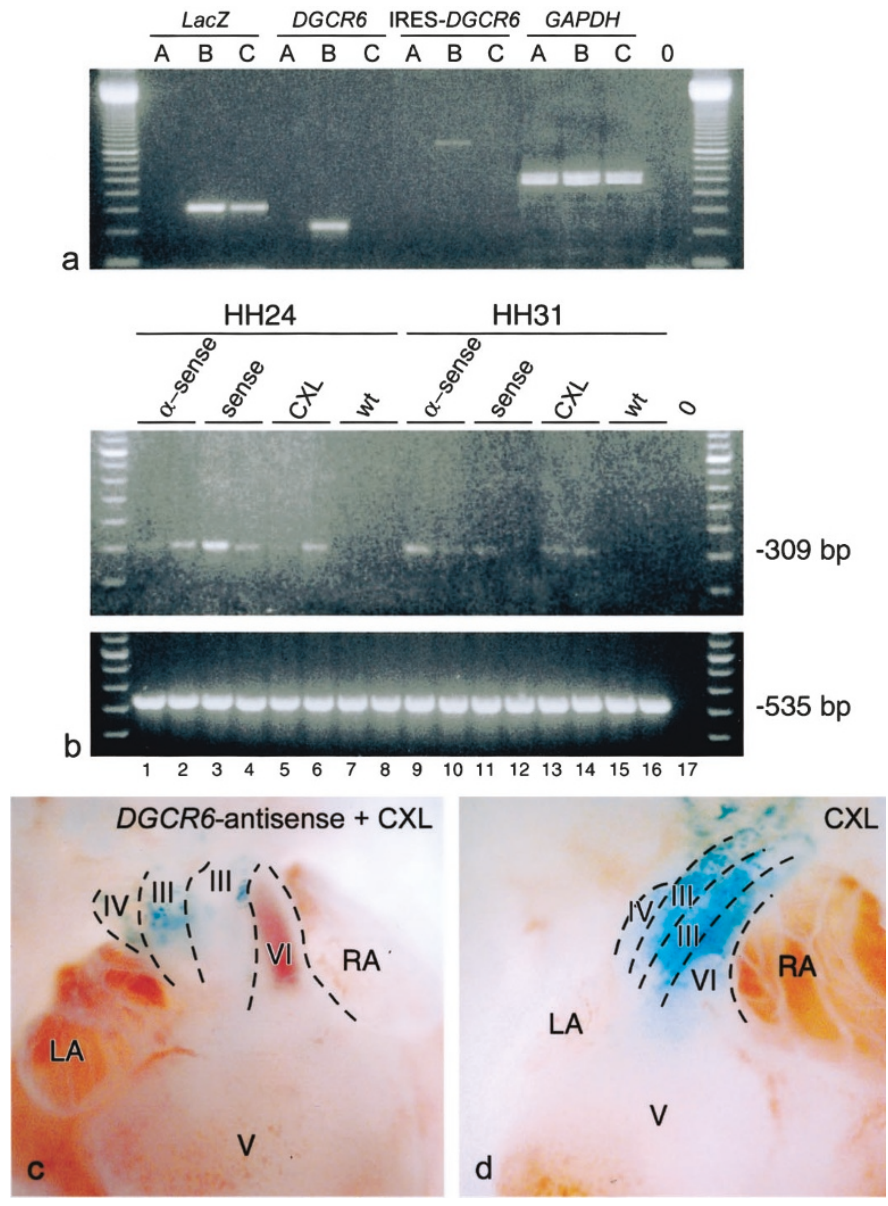

Figure 3. Identification of infectious retroviral particles. (a) RT-PCR on RNA from $\mathrm{R} 2$ rat fibroblast transduced with conditioned medium from packaging cells producing no virus (A, control), DGCR6-antisense virus $(B)$, and CXL control virus $(C)$. Primers for LacZ identified particles in $B$ and $C$, whereas primers for DGCR6 and for IRES-DGCR6 only amplified from sample $B$. GAPDH primers identified template RNA in all samples. "0" represents sample without template (negative control). (b) RT-PCR on RNA samples from embryonic hearts (odd-numbered lanes), pharyngeal arch mesenchyme (lanes 2, 4, 6, 8), and on pharyngeal arch arteries (lanes 10, 12, 14, 16). RNA was isolated from untreated embryos (wt), from antisense DGCR6 ( $\alpha$-sense), full-length sense DGCR6 (sense), and CXL treated embryos. $0=$ negative control. Primers for LacZ resulted in amplification of a 309-bp product, and for GAPDH in a 535-bp product. $(c, d)$ Frontal view on the X-gal stained hearts of stage $\mathrm{HH} 30$ embryos of which the NCC were transduced with a mixture of DGCR6-antisense and CXL $(c)$, and with CXL alone $(d)$. X-gal staining shows essentially identical distribution patterns of transduced cells, indicating that the attenuation of DGCR6 does not result in abnormal NCC migration or cell death.

DGCR6-antisense and -partial sense groups, is unlikely and is underlined by the lack of cardiovascular defects in these embryos. All changes were transient as no significant differences in expression could be measured at HH30, despite perturbed morphology at this stage.

\section{DISCUSSION}

Expression and structural aspects of DGCR6. Our results strongly indicate a role for $D G C R 6$ in cardiovascular development. DGCR6 was first described (33) as localized to the DiGeorge critical region and as hemizygously deleted in four 
Table 1. Cardiovascular morphology after retroviral infection

\begin{tabular}{lcccc}
\hline & & DGCR6 & & CXL \\
\cline { 2 - 4 } & Antisense $(n=31)$ & Part-sense $(n=22)$ & Sense $(n=17)$ & Control $(n=20)$ \\
\hline Subarterial VSD/DORV & $14(45 \%)$ & $15(68 \%)$ & 0 & 0 \\
Absent PAA-IV* (right) & $4(13 \%)$ & $2(9 \%)$ & 0 & 0 \\
Persistant PAA-IV* (left) & $1(3 \%)$ & $3(14 \%)$ & 0 & 0 \\
\hline
\end{tabular}

* PAA-IV, fourth pharyngeal arch artery.

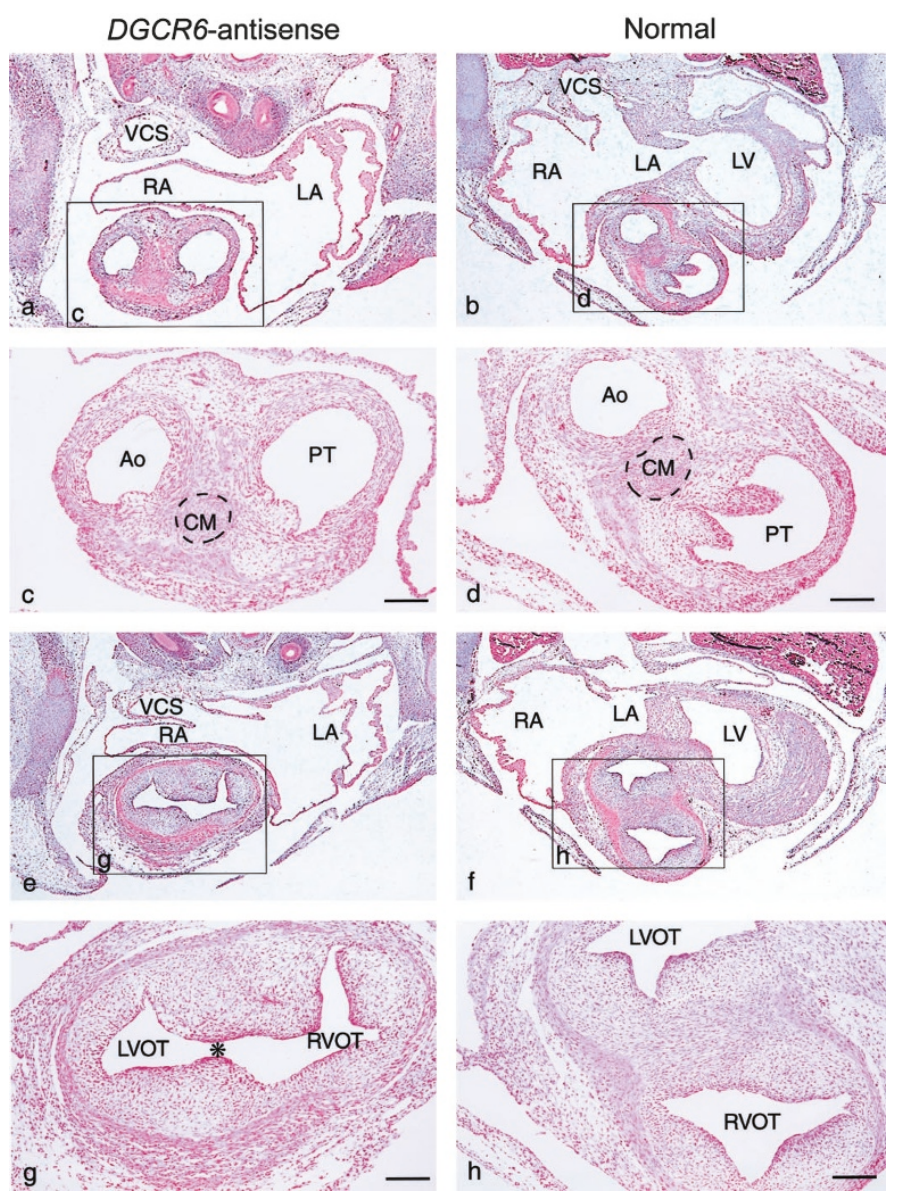

Figure 4. Cardiac anomalies. Sections through the outflow tract at HH31, after transduction with the DGCR6-antisense construct $(a, c, e, g)$, and control embryos $(b, d, f, h)$. Panels $a, b, e, f$ are overviews of the heart in which the other panels are marked. $(b, c, d)$ Aortic $(A o)$ and pulmonary $(P T)$ orifices, just above the level of the semilunar valves, with the NCC-derived condensed mesenchyme $(C M)$ normally situated centrally between the orifices $(d)$, and malpositioned ventrally after transduction $(c) .(e, g)$ DORV (asterisk, $g$ ). The left ventricular outflow tract $(L V O T)$ connected to the aorta is malpositioned to the right $(g)$ compared with the control embryo $(h)$, and disconnects to the right ventricular outflow tract $(R V O T)$. $R A$, right atrium; $L A$, left atrium; $L V$, left ventricle; $V C S$, superior caval vein. Bar $=10 \mu \mathrm{m}$.

DGS patients. The human gene showed homology to the laminin gamma-1 chain and to the Drosophila gonadal protein GDL, of which only homology to the latter was conserved in the chicken sequence of DGCR6. The potential single transmembrane domain and phosphorylation sites suggest a receptor-like function for DGCR6, but no functional homology to any known receptor family has been found to date. Murine Dgcr6 was expressed during embryogenesis in the pharyngeal arch mesenchyme and in the central and peripheral nervous system (34). We confirmed these expression data in chicken

\section{DGCR6-antisense}
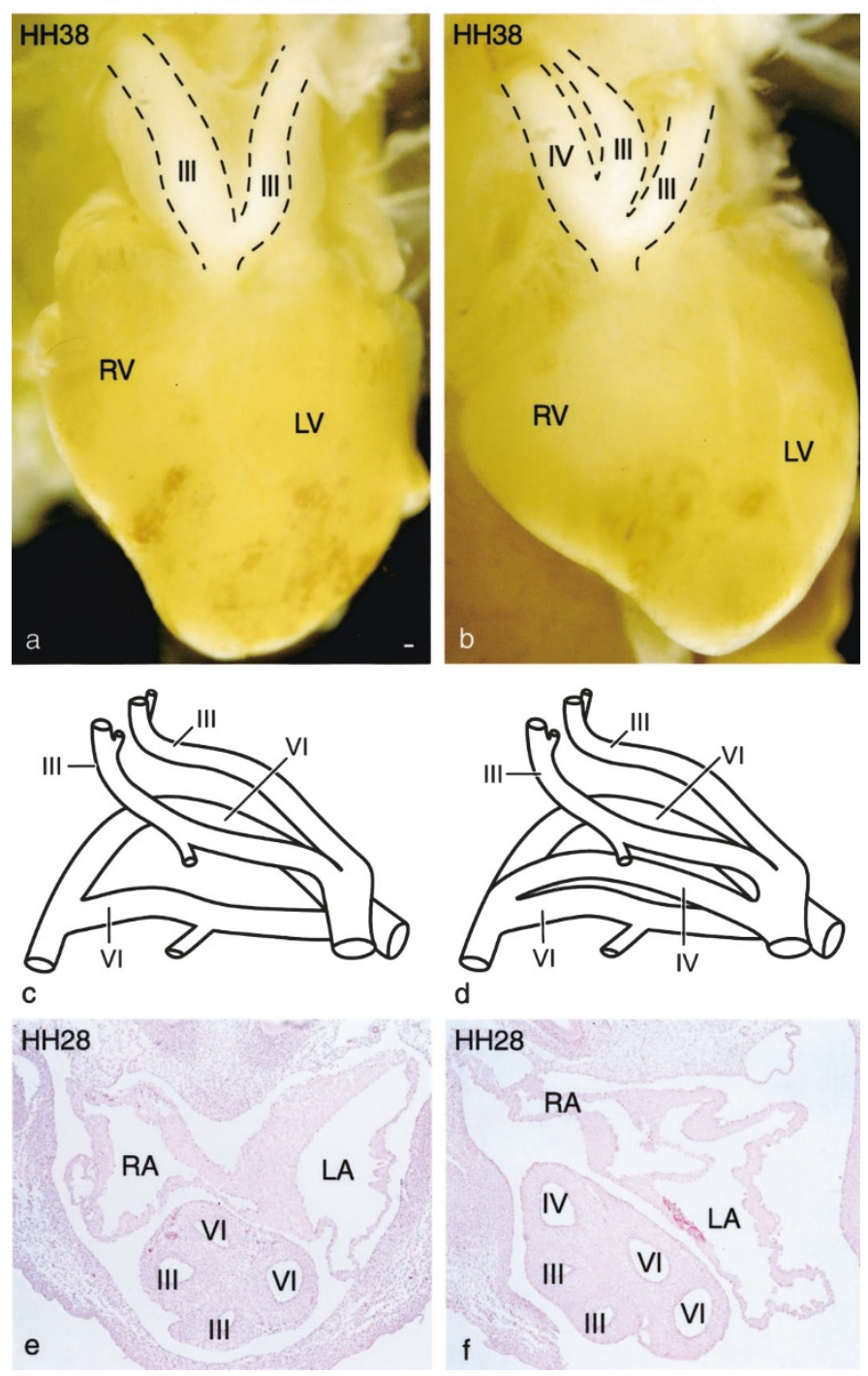

Figure 5. Vascular anomalies. $(a, b)$ Frontal view on the heart. Note that the right fourth pharyngeal arch artery $(b)$ is missing from the DGCR6-antisense transduced embryo $(a)$. $(c, d)$ Schematic representation of the arch arteries at HH28 showing absence of the right fourth arch artery (c). In the normal situation $(d)$, blood from the left ventricle runs into a left and right brachiocephalic arteries (III) and into a right ascending aorta $(I V)$. From the right ventricle the blood runs bilaterally through the sixth arch arteries (arterial ducts) into the dorsal aorta. $(e, f)$ Sections through the pharyngeal arch region, showing absence of the right fourth arch artery $(e)$, compared with normal $(f)$. Bar $=50 \mu \mathrm{m}$.

embryos and, in addition, showed a pattern of expression that was initially broad, but became gradually restricted to neural crest-derived tissues. With respect to cardiovascular development, it is of special interest that the myocardium does not express DGCR6, whereas mRNA is abundant during the im- 

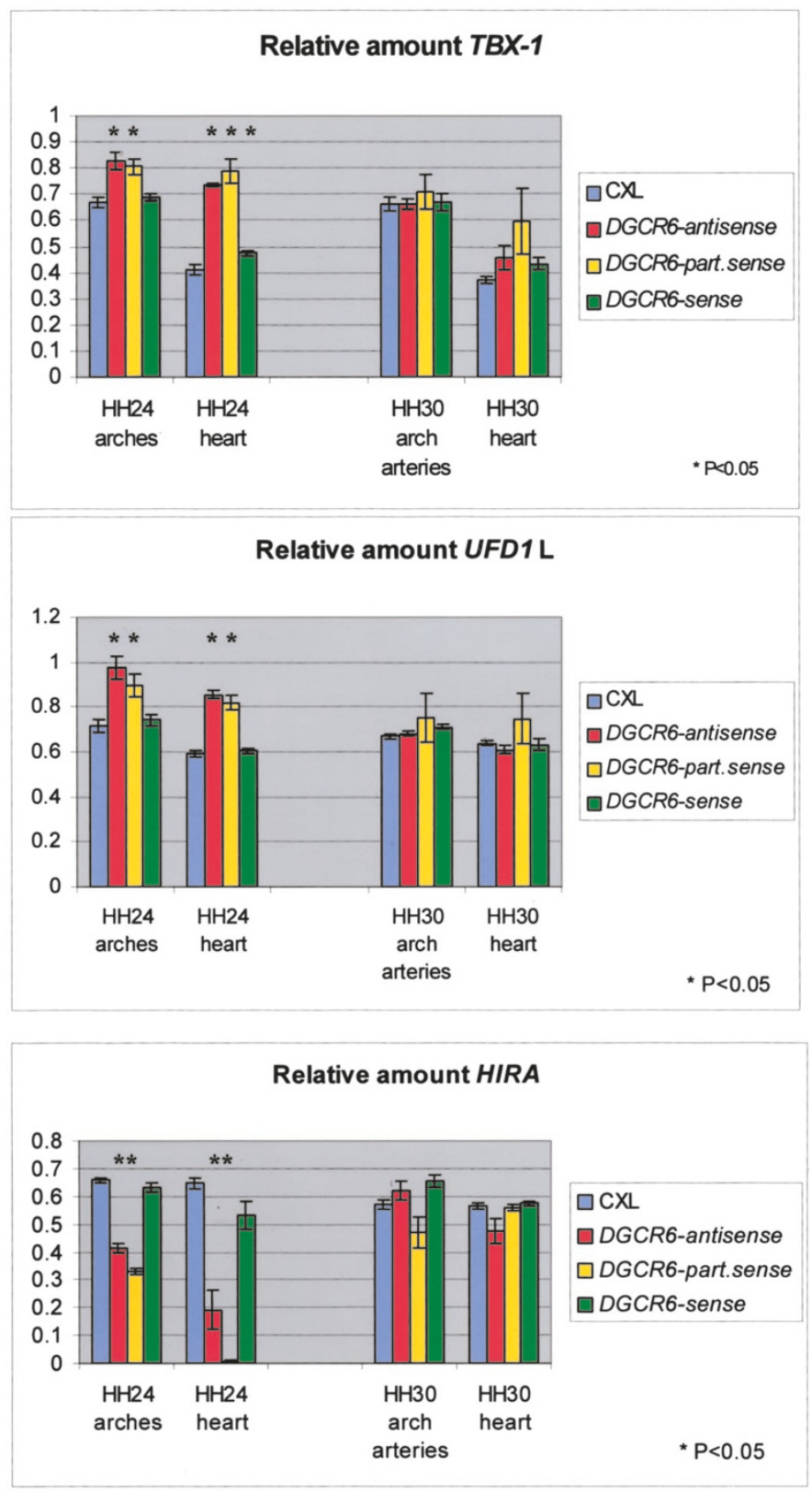

Figure 6. DiGeorge candidate gene expression profiles. Relative expression of TBX-1, UFD1L, and HIRA in hearts and aortic arches at stage HH24 and 30. NCC of stage HH10 embryos were infected with DGCR6-antisense, -partial sense, -sense, or control ( $C X L)$ retroviruses and embryos ( $n=5$ in each group) were reincubated to stage $\mathrm{HH} 24$ or $\mathrm{HH} 30$. Hearts and aortic arch mesenchyme (HH24) or arch arteries (HH30) were microdissected and used for real time RT-PCR. From each sample, amplifications were performed for GAPDH and for the gene of interest within one experiment. $\mathrm{Ct}$ values were normalized to GAPDH for cDNA input, and means and SEM were calculated. Asterisks $(a-c)$ represent the groups that show significant differences $(t$ test, $p<0.05)$ of DGCR6-retrovirus-treated groups compared with CXL treatment. TBX-1 and UFDIL were transiently up-regulated upon transduction with DGCR6antisense and -partial sense constructs in both arches and hearts. HIRA, on the other hand, was down-regulated dramatically in both groups. Transduction with the DGCR6-sense construct did not result in changes in expression, except for a slight increase in TBX-1 in the heart at stage HH24 ( $p=0.037)$.

portant stages of pharyngeal arch remodeling. DGCR6 expression in the arches is not confined to the neural crest-derived mesenchyme, as has been shown, for example, for the endo-
thelin-A receptor (26), or to the mesoderm and epithelia like $T b x-1$ (44). The DGCR6 expression pattern most closely resembles that of $\operatorname{Ufd} 1 L(14,45)$. It appears that the DiGeorge candidate genes, as described for other genes (46), show distinct and overlapping expression patterns in the pharyngeal arches during crucial stages of vascular remodeling.

Morphology after transduction of NCC with DGCR6. We decided to target DGCR6 expression in vivo, specifically in NCC, by means of a retroviral transduction technique. Recently, we have shown the ability to efficiently target gene expression of the ubiquitin fusion degradation-like protein-1 UFDIL (14), and of the transcription factor ETS (47) in chicken embryos by retroviral delivery of antisense messages. Transfection data show that expression was reduced to $41-53 \%$ upon introduction of an antisense construct for DGCR6 in an in vitro system. This would be in line with the presumed protein levels in a hemizygously deleted DGS patient. CXL-driven $\mathrm{LacZ}$ markergene expression, as previously shown by our group, has proven its use for NCC transduction and NCC tracing in vivo (3-5). Targeting DGCR6 expression in cardiac NCC using these procedures resulted in abnormal development of the cardiac outflow tract and pharyngeal arch-related vasculature reminiscent to the DiGeorge phenotype.

The cardiac phenotype in our chicken model included subarterial VSD/DORV (45-68\%). The neural crest-derived aortopulmonary septum (APS) in these embryos was severely hypoplastic, and did not reach the interventricular septum. Furthermore, because the aorta was malpositioned, the APS was not aligned with the ventricular septum resulting in a persisting left-right communication. This malformation has been described in human patients as a subarterial VSD and appears related to 22q1.1 deletions (8). This in contrast to the "lower" and smaller perimembranous VSD, which are present in deletion patients, but are not indicative for del22q11. The development of the fourth pharyngeal arch arteries was severely affected in $16-23 \%$ of the embryos, whereas third and sixth arch arteries developed normally. The abnormal persistence of the left and complete absence of the right fourth arch artery suggests that this segment is bilaterally affected. When avian and mammalian vascular development are compared, absence of the right fourth arch artery in chickens equals the type-B interruption of the aortic arch (IAA-B). This phenotype is highly indicative for chromosome 22 deletion syndrome, inasmuch as more than $50 \%$ of patients with this phenotype suffer from deletions in 22q11 (8).

It is remarkable that targeting DGCR6 function in this chicken model results in a similar vascular phenotype as has been described for the $T b x 1^{+/-}$mouse models (16-18). Whereas the initial specification of the pharyngeal arch arteries appears normal in both chickens and mice (48), the remodeling of the fourth aortic arch artery is seriously hampered, whereas the third and sixth arch arteries develop normally. In addition, in both models the NCC migration patterning appears not to be disturbed (49). This suggests a close relationship between $D G C R 6$ and $T B X-1$ and between NCC and the TBX-1-positive surrounding cells during cardiovascular development, possibly through growth factors like Fgf-8 or -10 $(24,50)$ or VEGF164 (21). 
DGCR6 modifies expression of TBX-1, UFD1L, and HIRA. Our data provide the first evidence for a contiguous type of functional interaction between gene products encoded by different genes within the DiGeorge critical region. We showed that interference with DGCR6 in cardiac NCC influenced the expression levels of TBX-1, UFD1L, and HIRA in the pharyngeal arches and in the heart, even before morphologic anomalies were present. When morphology responds, i.e. around HH30, expression levels of these genes have returned to normal. This is in line with the expression profile of DGCR6 during development. In early development (HH10-HH28), DGCR6 mRNA was abundantly present in neural crestpopulated areas in the embryo like the pharyngeal arches, the frontonasal mesenchyme, and the media of the pharyngeal arch arteries. In these areas, DGCR6 co-localizes with UFDIL (14, 45) and HIRA (51), and is present in close proximity to $T B X-1$-positive areas like the endoderm and ectoderm of the pharyngeal pouches and the mesodermal core of the pharyngeal arches (20). Because cardiovascular expression of DGCR6 becomes restricted to the parasympathetic ganglia on the heart after $\mathrm{HH} 28$, the effect of the antisense construct was expected to diminish in the heart and vessels. Apparently, the transient alteration of gene expression during remodeling stages was sufficient for cardiovascular anomalies to develop. The observation that the partial sense construct, based on the originally described DGCR6 sequence (33), induced the same cardiovascular phenotype and gene expression profile as the antisense construct suggests a dominant negative effect for this gene product. Based on its receptor-like structure, this suggestion appears feasible, as the partial construct codes for an aminotruncated peptide that lacks the potential transmembrane domain and 5' phosphorylation sites and can therefore be considered soluble.

The increase in $T B X-1$ and $U F D 1 L$ levels after the attenuation of DGCR6 indicates a repressor function for DGCR6 during normal development (Fig. 7). On the other hand, the decreases in HIRA levels show a positive regulatory mechanism. Considering the expression patterns of $T B X-1$ and the fact that DGCR6 was attenuated in NCC, DGCR6-mediated repression should be considered in terms of a cellular interaction mechanism, instead of cis- or trans-activation of gene expression as has been recently described for the $T b x-1$ promoter (20). Whether that also accounts for UFDIL and HIRA needs further investigation. A repressor function for DGCR6 is supported by the mouse models in which parts of chromosome 16, including $D g c r 6$, are deleted $(18,52)$. These mice do not show cardiovascular anomalies. However, the lack of typical phenotypic DGS characteristics does not rule out involvement of modifier genes, especially of repressors. When $T b x-1$ is homozygously present, the absence of a repressor is not expected to have a major effect. However, when protein levels drop due to hemizygosity, the presence of a repressor could further diminish these levels and worsen the phenotype. In line with this hypothesis the recovery from arterial growth delay, as described by Lindsay and co-workers (48), in the $D f 1 /+$ mouse model, could be explained by the expression pattern of $D G C R 6$ and its repressor function on $T b x-1$, i.e. expression of DGCR6 is high in the smooth muscle cells of the pharyngeal arch
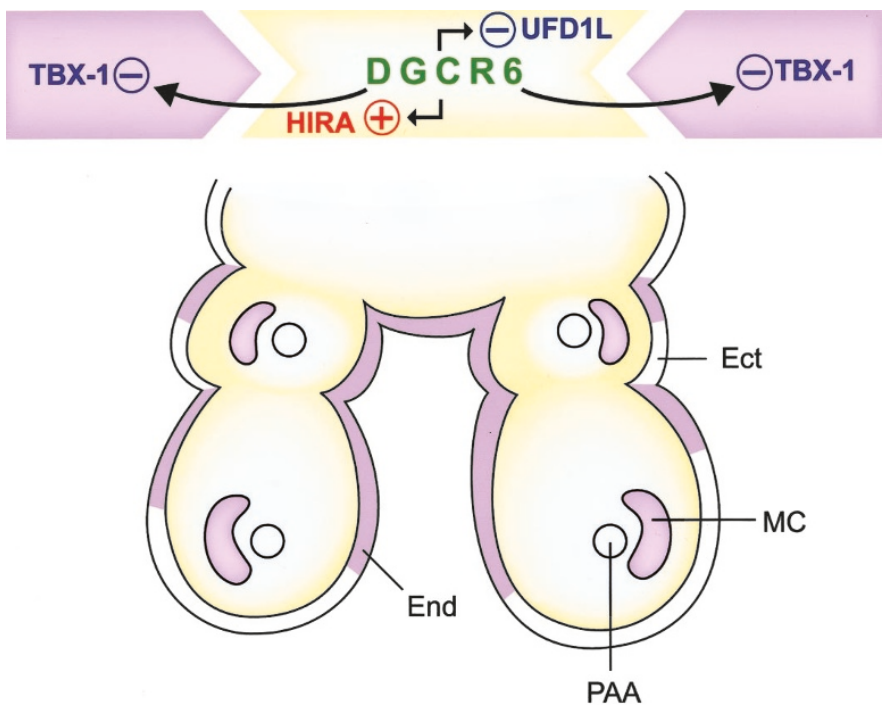

Figure 7. Interaction model in the pharyngeal arch arteries. Hypothetical interaction of DGCR6 with other DiGeorge candidate genes in the pharyngeal arches during critical phases of cardiovascular remodelling. DGCR6 is expressed in the neural crest-derived pharyngeal mesenchyme (yellow), but not in the ectoderm $(E c t)$ or endoderm $(E n d) . T B X-1$, on the other hand, shows distinct expression in the latter two structures (purple) and in the mesodermal core $(M C)$ of the arches. Attenuation of DGCR6 in NCC results in an up-regulation of $T B X-1$ and $U F D I L$, and in down-regulation of HIRA. This suggests a repressive effect on $T B X-1$ and $U F D 1 L$, and activation of HIRA during normal development. $P A A$, pharyngeal arch artery.

arteries around $\mathrm{HH} 28$, but diminishes after this stage. This decrease of DGCR6 in the vessels would relieve the pressure on $T B X-1$ expression, allowing a recovery of gene expression and a (partial) restoration of vessel morphology.

Although a repressor function for DGCR6 on TBX-1 would explain several characteristics of described mouse models, it is more difficult to understand why our model, in which $T B X-1$ is elevated, evokes a similar phenotype as models in which $T b x-1$ is targeted. However, an increase in $T b x-1$ in the mouse model described by Merscher and co-workers (16) causes defects that are similar to $T b x-1$ haploinsufficiency, as well. Possibly a temporal disbalance in gene expression profiles during critical stages of cardiovascular development is responsible for the described anomalies. On the other hand, the temporal decrease of UFDIL and increase of HIRA in our model might be instrumental for involvement of additional gene cascades all leading to a similar developmental response. The fact that attenuation of UFDIL by the same antisense retrovirus technique in chicken embryos primarily evokes conotruncal anomalies supports this hypothesis (14). Detailed analysis of downstream effectors will be needed to sort out these possibilities.

Acknowledgments. The authors thank Tim Dalebout, Liesbeth van Iperen, and Henri Kerkdijk for expert technical assistance. We also thank Dr. Margot Bartelings for her help in phenotyping, Jan Lens for the artwork, and Dr. Suzanne Demczuk for providing the human DGCR6 cDNA.

\section{REFERENCES}

1. Goldmuntz E, Emanuel BS 1997 Genetic disorders of cardiac morphogenesis. The DiGeorge and velocardiofacial syndromes. Circ Res 80:437-443 
2. Erickson CA, Reedy MV 1998 Neural crest development: the interplay between morphogenesis and cell differentiation. Curr Top Dev Biol 40:177-209

3. Poelmann RE, Mikawa T, Gittenberger-de Groot AC 1998 Neural crest cells in outflow tract septation of the embryonic chicken heart: differentiation and apoptosis. Dev Dyn 212:373-384

4. Noden DM, Poelmann RE, Gittenberger-de Groot AC 1995 Cell origins and tissue boundaries during outflow tract development. Trends Cardiovasc Med 5:69-75

5. Bergwerff M, Verberne ME, DeRuiter MC, Poelmann RE, Gittenberger-de Groot AC 1998 Neural crest cell contribution to the developing circulatory system: implications for vascular morphology? Circ Res 82:221-231

6. Kirby ML 1993 Cellular and molecular contributions of the cardiac neural crest to cardiovascular development. Trends Cardiovasc Med 3:18-23

7. Poelmann RE, Gittenberger-de Groot AC 1999 A subpopulation of apoptosis-prone cardiac neural crest cells targets to the venous pole: multiple functions in heart development? Dev Biol 207:271-286

8. Momma K, Matsuoka R, Takao A 1999 Aortic arch anomalies associated with chromosome 22q11 deletion (CATCH 22). Pediatr Cardiol 20:97-102

9. Gittenberger-de Groot AC, Poelmann RE, Bartelings MM 1997 Embryology of congenital heart disease. In: Braunwald E, Freedom R (eds) Congenital Heart Disease. Current Medicine, Philadelphia, pp 3.1-3.10

10. Kurahashi H, Shaikh TH, Hu P, Roe BA, Emanuel BS, Budarf ML 2000 Regions of genomic instability on $22 \mathrm{q} 11$ and $11 \mathrm{q} 23$ as the etiology for the recurrent constitutional $\mathrm{t}(11 ; 22)$. Hum Mol Genet 9:1665-1670

11. Shaikh TH, Kurahashi H, Saitta SC, O'Hare AM, Hu P, Roe BA, Driscoll DA, McDonald-McGinn DM, Zackai EH, Budarf ML, Emanuel BS 2000 Chromosome 22 -specific low copy repeats and the 22q11.2 deletion syndrome: genomic organization and deletion endpoint analysis. Hum Mol Genet 9:489-501

12. Llevadot R, Scambler P, Estivill X, Pritchard M 1996 Genomic organization of tuple1/hira: a gene implicated in DiGeorge syndrome. Mamm Genome 7:911-914

13. Yamagishi H, Garg V, Matsuoka R, Thomas T, Srivastava D 1999 A molecular pathway revealing a genetic basis for human cardiac and craniofacial defects. Science 283:1158-1161

14. Yamagishi C, Hierck BP, Gittenberger-de Groot AC, Yamagishi H, Srivastava D 2003 Functional attenuation of Ufd1L, a 22q11.2 deletion syndrome candidate gene, leads to cardiac outflow septation defects in chicken embryos. Pediatr Res 53:546553

15. Guris DL, Fantes J, Tara D, Druker BJ, Imamoto A 2001 Mice lacking the homologue of the human 22q11.2 gene CRKL phenocopy neurocristopathies of DiGeorge syndrome. Nat Genet 27:293-298

16. Merscher S, Funke B, Epstein JA, Heyer J, Puech A, Lu MM, Xavier RJ, Demay MB, Russell RG, Factor S, Tokooya K, Jore BS, Lopez M, Pandita RK, Lia M, Carrion D, Xu H, Schorle H, Kobler JB, Scambler P, Wynshaw-Boris A, Skoultchi AI, Morrow BE, Kucherlapati R 2001 TBX1 is responsible for cardiovascular defects in velocardio-facial/DiGeorge syndrome. Cell 104:619-629

17. Jerome LA, Papaioannou VE 2001 DiGeorge syndrome phenotype in mice mutant for the T-box gene, Tbxl. Nat Genet 27:286-291

18. Lindsay EA, Vitelli F, Su H, Morishima M, Huynh T, Pramparo T, Jurecic V, Ogunrinu G, Sutherland HF, Scambler PJ, Bradley A, Baldini A 2001 Tbxl haploinsufficieny in the DiGeorge syndrome region causes aortic arch defects in mice. Nature 410:97-101

19. McQuade L, Christodoulou J, Budarf M, Sachdev R, Wilson M, Emanuel B, Colley A 1999 Patient with a 22q11.2 deletion with no overlap of the minimal DiGeorge syndrome critical region (MDGCR). Am J Med Genet 86:27-33

20. Yamagishi H, Maeda J, Hu T, McAnally J, Conway SJ, Kume T, Meyers EN, Yamagishi C, Srivastava D 2003 Tbxl is regulated by tissue-specific forkhead proteins through a common Sonic hedgehog-responsive enhancer. Genes Dev 17:269-281

21. Stalmans I, Lambrechts D, De Smet F, Jansen S, Wang J, Maity S, Kneer P, von der Ohe M, Swillen A, Maes C, Gewillig M, Molin DG, Hellings P, Boetel T, Haardt M, Compernolle V, Dewerchin M, Plaisance S, Vlietinck R, Emanuel B, Gittenberger-de Groot AC, Esguerra CV, Scambler P, Morrow B, Driscoll DA, Moons L, Esguerra CV, Carmeliet G, Behn-Krappa A, DeVviendt K, Collen D, Conway SJ, Carmeliet P 2003 VEGF: a modifier of the del22q11 (DiGeorge) syndrome? Nat Med 9:173-182

22. Abu-Issa R, Smyth G, Smoak I, Yamamura K, Meyers EN 2002 Fgf8 is required for pharyngeal arch and cardiovascular development in the mouse. Development 129:4613-4625

23. Frank DU, Fotheringham LK, Brewer JA, Muglia LJ, Tristani-Firouzi M, Capecchi MR, Moon AM 2002 An Fgf8 mouse mutant phenocopies human 22q11 deletion syndrome. Development 129:4591-4603

24. Vitelli F, Taddei I, Morishima M, Meyers EN, Lindsay EA, Baldini A 2002 A genetic link between $T b x I$ and fibroblast growth factor signaling. Development 129:46054611

25. Kurihara Y, Kurihara H, Oda H, Maemura K, Nagai R, Ishikawa T, Yazaki Y 1995 Aortic arch malformations and ventricular septal defect in mice deficient in endothelin-1. J Clin Invest 96:293-300

26. Clouthier DE, Hosoda K, Richardson JA, Williams SC, Yanagisawa H, Kuwaki T, Kumada M, Hammer RE, Yanagisawa M 1998 Cranial and cardiac neural crest defects in endothelin-A receptor-deficient mice. Development 125:813-824

27. Yanagisawa H, Yanagisawa M, Kapur RP, Richardson JA, Williams SC, Clouthier DE, de Wit D, Emoto N, Hammer RE 1998 Dual genetic pathways of endothelin- mediated intercellular signaling revealed by targeted disruption of endothelin converting enzyme-1 gene. Development 125:825-836

28. Bartram U, Molin DG, Wisse LJ, Mohamad A, Sanford LP, Doetschman T, Speer CP, Poelmann RE, Gittenberger-de Groot AC 2001 Double-outlet right ventricle and overriding tricuspid valve reflect disturbances of looping, myocardialization, endocardial cushion differentiation, and apoptosis in TGF $\beta 2$-knockout mice. Circulation 103:2745-2752

29. Iida K, Koseki H, Kakinuma H, Kato N, Mizutani-Koseki Y, Ohuchi H, Yoshioka H, Noji S, Kawamura K, Kataoka Y, Ueno F, Taniguchi M, Yoshida N, Sugiyama T, Miura N 1997 Essential roles of the winged helix transcription factor MFH-1 in aortic arch patterning and skeletogenesis. Development 124:4627-4638

30. Winnier GE, Kume T, Deng K, Rogers R, Bundy J, Raines C, Walter MA, Hogan BL, Conway SJ 1999 Roles for the winged helix transcription factors MF1 and MFH1 in cardiovascular development revealed by nonallelic noncomplementation of null alleles. Dev Biol 213:418-431

31. Franz T 1989 Persistent truncus arteriosus in the Splotch mutant mouse. Anat Embryol (Berl) 180:457-464

32. Feiner L, Webber AL, Brown CB, Lu MM, Jia L, Feinstein P, Mombaerts P, Epstein JA, Raper JA 2001 Targeted disruption of semaphorin 3C leads to persistent truncus arteriosus and aortic arch interruption. Development 128:3061-3070

33. Demczuk S, Thomas G, Aurias A 1996 Isolation of a novel gene from the DiGeorge Syndrome critical region with homology to Drosophila $g d l$ and to human LAMCI genes. Hum Mol Genet 5:633-638

34. Lindsay EA, Baldini A 1997 A mouse gene (Dgcr6) related to the Drosophila gonadal gene is expressed in early embryogenesis and is the homolog of a human gene deleted in DiGeorge syndrome. Cytogenet Cell Genet 79:243-247

35. Hierck BP, Poelmann RE, van Iperen L, Brouwer A, Gittenberger-de Groot AC 1996 Differential expression of $\alpha 6$ and other subunits of laminin binding integrins during development of the murine heart. Dev Dyn 206:100-111

36. Hierck BP, Gittenberger-de Groot AC, van Iperen L, Brouwer A, Poelmann RE 1996 Expression of the beta- 4 integrin subunit in the mouse heart during embryonic development: retinoic acid advances beta-4 expression. Dev Dyn 207:89-103

37. Wilkinson DG 1995 RNA detection using non-radioactive in situ hybridization. Curr Opin Biotechnol 6:20-23

38. Mima T, Ueno H, Fischman DA, Williams LT, Mikawa T 1995 Fibroblast growth factor receptor is required for in vivo cardiac myocyte proliferation at early embryonic stages of heart development. Proc Natl Acad Sci U S A 92:467-471

39. Mikawa T, Fischman DA, Dougherty JP, Brown AM 1991 In vivo analysis of a new lacZ retrovirus vector suitable for cell lineage marking in avian and other species. Exp Cell Res 195:516-523

40. Cohen-Tannoudji M, Vandormael-Pournin S, Drezen J, Mercier P, Babinet C, Morello D 2000 lacZ sequences prevent regulated expression of housekeeping genes. Mech Dev 90:29-39

41. Lau S, Jardine K, McBurney MW 1999 DNA methylation pattern of a tandemly repeated LacZ transgene indicates that most copies are silent. Dev Dyn 215:126-138

42. Vagner S, Galy B, Pyronnet S 2001 Irresistible IRES: attracting the translation machinery to internal ribosome entry sites. EMBO Rep 2:893-898

43. Pfaffl MW 2001 A new mathematical model for relative quantification in real-time RT- PCR. Nucleic Acids Res 29:e45

44. Chapman DL, Garvey N, Hancock S, Alexiou M, Agulnik SI, Gibson-Brown JJ, Cebra-Thomas J, Bollag RJ, Silver LM, Papaioannou VE 1996 Expression of the T-box family genes, Tbxl-Tbx5, during early mouse development. Dev Dyn 206:379-390

45. Pizzuti A, Novelli G, Ratti A, Amati F, Mari A, Calabrese G, Nicolis S, Silani V, Marino B, Scarlato G, Ottolenghi S, Dallapiccola B 1997 Ufd11, a developmentally expressed ubiquitination gene, is deleted in $\mathrm{CATCH} 22$ syndrome. Hum Mol Genet 6:259-265

46. Clouthier DE, Williams SC, Yanagisawa H, Wieduwilt M, Richardson JA, Yanagisawa M 2000 Signaling pathways crucial for craniofacial development revealed by endothelin-A receptor-deficient mice. Dev Biol 217:10-24

47. Lie-Venema H, Gittenberger-de Groot AC, van Empel LJ, Boot MJ, Kerkdijk H, de Kant E, DeRuiter MC 2003 Ets-1 and Ets-2 transcription factors are essential for normal coronary and myocardial development in chicken embryos. Circ Res 92:749756

48. Lindsay EA, Baldini A 2001 Recovery from arterial growth delay reduces penetrance of cardiovascular defects in mice deleted for the DiGeorge syndrome region. Hum Mol Genet 10:997-1002

49. Vitelli F, Morishima M, Taddei I, Lindsay EA, Baldini A 2002 Tbx1 mutation causes multiple cardiovascular defects and disrupts neural crest and cranial nerve migratory pathways. Hum Mol Genet 11:915-922

50. Kochilas L, Merscher-Gomez S, Lu MM, Potluri V, Liao J, Kucherlapati R, Morrow B, Epstein JA 2002 The role of neural crest during cardiac development in a mouse model of DiGeorge syndrome. Dev Biol 251:157-166

51. Roberts C, Daw SC, Halford S, Scambler PJ 1997 Cloning and developmental expression analysis of chick Hira (Chira), a candidate gene for DiGeorge syndrome. Hum Mol Genet 6:237-245

52. Puech A, Saint-Jore B, Merscher S, Russell RG, Cherif D, Sirotkin H, Xu H, Factor S, Kucherlapati R, Skoultchi AI 2000 Normal cardiovascular development in mice deficient for 16 genes in $550 \mathrm{~kb}$ of the velocardiofacial/DiGeorge syndrome region. Proc Natl Acad Sci U S A 97:10090-10095 